\title{
СОЦИАЛЬНАЯ АДАПТАЦИЯ И КАЧЕСТВО ЖИЗНИ БОЛЬНЫХ ЭПИЛЕПСИЕЙ
}

\author{
*Г.А. Дущанова, Г.У. Туксанбаева \\ Южно-Казахстанская государственная фармацевтическая академия, г.Шымкент, Казахстан
}

Исследование направлено на изучение качества жизни и социальной адаптации больных идиопатической эпилепсией, проведено на 120 больных идиопатической эпилепсией из числа пациентов неврологического отделения и поликлиники Областной клинической больницы г. Шымкента. При исследовании выявлено, что не зависимо от формы идиопатической эпилепсии, пола, возраста больных - 63 (52,5\%) человека проживают в сельской местности (районах, селах) области, а 57 (47,5\%) пациентов в городе. Но наличие высшего и средне-специального образования у больных идиопатической эпилепсией, проживавших в городе наблюдалось в большинстве случаев, чем среди пациентов, проживавших в сельской местности. Средняя продолжительность заболева-

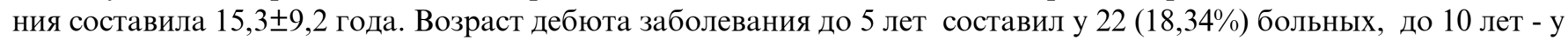
36 (30\%) пациентов, до 15 лет выявлено у 44 (36,66\%) больных, у 18 (15\%) человек - после 15 лет. Пик дебюта заболевания эпилепсии проявился до 15 лет в большинстве случаев у 36,66\% больных. Анализ опросника КЖ больных ИЭ показал зависимость КЖ от уровня образования, занятости на работе, учебной деятельности, инвалидизации, состояния когнитивных функций - уровня интеллекта, их положения в социуме. Больные ИЭ оценили свое качество жизни, как плохое, что свидетельствовало об их не высоком реабилитационном потенциале, вероятно, связанным, с мало эффективной, неадекватной АЭ терапией или недоступностью дорогостоящих лекарственных средств. Отмечено, что на КЖ больных ИЭ влияли демографические и клинические показатели (пол, возраст больных, формы эпилепсии, тип, частота припадков, место проживания, образование), а также степень когнитивных нарушений.

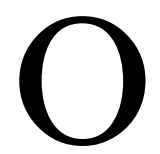
храна здоровья населения, снижение заболеваемости, инвалидности и смертности, увеличение продолжительности жизни и периода профессиональной активности, повышение уровня социального функционирования и качества жизни (КЖ) человека являются приоритетными направлениями социальной политики любого развитого государства. Улучшение КЖ и реабилитация больных эпилепсией является одной из приоритетных целей современной эпилептологии. Социальные аспекты ведения больных эпилепсией, вопросы качества их жизни становятся в последние годы одними из наиболее важных проблем медицины.

Проблема действительно имеет огромную социальную значимость, так как только в Казахстане эпилепсией страдают более 36 тысяч человек, 60\% из них - дети. Об эпилепсии в Казахстане до сих пор говорят только шепотом. Страх лишиться работы, осуждения и непонимание со стороны родных и близких, коллектива и, лишения водительских прав заставляет большую часть пациентов скрывать свою болезнь.

Для успешного лечения есть весь спектр необходимых медикаментов. Эпилепсия *e-mail: ellichka.zh@mail.ru только в 20\% случаев не поддается лечению. Вместе с тем, достижения фармакотерапии не привели к значительным изменениям в социальном статусе больных эпилепсией, что связано с продолжающейся стигматизацией этих лиц обществом. Сотрудниками кафедры неврологии ЮКГМА, а в дальнейшем ЮКГФА, начиная с 2006 года проводится регистр эпилепсии в Южно-Казахстанской области и областном центре - г. Шымкенте. Проведенное исследование позволило получить комплексную клинико-эпидемиологическую картину эпилепсии в Южно-Казахстанской области. Результаты исследования показали, что стандартизированное по полу и возрасту значение распространенности активной эпилепсии для всей исследуемой популяции составило - 4,55 случая на 1000 человек населения, что несколько отличается от опубликованных усредненных значений распространенности эпилепсии для ряда регионов РФ - 3,4 и Казахстана.

Однако актуальность проблемы определяется не только и не столько распространенностью, сколько тяжестью заболевания, преимущественным началом в детском возрасте, прогредиентностью течения большинства ее 
форм, неблагоприятным влиянием припадков на мозг, частотой изменения психики. Развитие когнитивных и поведенческих нарушений негативно отражается на успешности их трудовой и социальной адаптации и в конечном счете приводит к снижению качества жизни.

В настоящее время в Казахстане не достаточно широко применяются адекватные инструментарии для оценки и анализа качества жизни больных эпилепсией, степени их социальной адаптации и стигматизации.

Целью исследования явилось изучение качество жизни и социальной адаптации больных идиопатической эпилепсией.

Кафедрой неврологи ЮКГФА в течение с 2010 по 2013 годы, проводятся исследования посвященные изучению социальной адаптации и качества жизни больных эпилепсией. В данной работе использовались материалы регистра эпилепсии, проводимые на кафедре с 2009 года.

Исследования проведены у 120 больных идиопатической эпилепсией из числа пациентов неврологического отделения и поликлиники Областной клинической больницы г. Шымкента.

В исследование были включены пациенты в возрасте от 16 до 55 лет, средний возраст со-

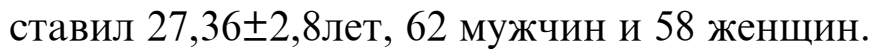
Критериями включения в исследование служили верифицированный диагноз идиопатической эпилепсии в соответствии критериями МКБ-10, отсутствие психотической и грубой неврологической очаговой симптоматики, возможность прохождения процедуры обследования.

В исследование не вошли больные с выраженным снижением интеллектуально - мнестических функций, деменцией и плохим знанием языка общения.

В клинико-статистическом анализе больных учитывались:

1) демографические характеристики (пол, возраст);

2) социальные характеристики (образование, занятость, наличие группы инвалидности, место проживания);
3) данные анамнеза (наличие наследственной отягощенности, перинатальной патологии, раннего органического поражения ЦНС, нейроинфекций, провоцирующих факторов фебрильных судорог);

4) характеристики заболевания (форма и длительность болезни, возраст дебюта припадков, наличие органической патологии головного мозга, частота, тип припадков, тяжесть и полиморфизм приступов, наличие в течение болезни эпистатусов);

5) терапия (базовый препарат, применявшийся для лечения пароксизмального состояния, эффект от проводимой терапии);

Для определения формы эпилепсии и вида припадков использовалась современная международная классификация припадков и эпилепсии (Киото, 1981; Нью-Дели, 1989). Тяжесть припадков определялась с помощью шкалы NHS3 (Национальная Британская шкала).

С учетом клинической картины, видов припадков, данных нейровизуализационных методов и электроэнцефалографических характеристик среди пациентов с идопатической эпилепсией были выделены клинические формы: у 11 (9,17\%) человек - юношеская миоклоническая эпилепсия (синдром Янца), у $65(54,16 \%)$ эпилепсия с генерализованными судорожными приступами пробуждения или сна, 18 (15\%) эпилепсии с приступами со специфическими способами провокации (большинство фотосенситивных эпилепсий), 26 $(21,67 \%)$ идиопатическая фокальная эпилепсия.

По социальному статусу больные эпилепсией, и с высшим образованием составили 28 $(23,33 \%)$ человек, со средним специальным образованием - 49 (40,83\%), со средним образованием - $19(15,83 \%)$ и инвалиды группы по данному заболеванию - 24 (20\%).

Больных ИЭ занятых, на работе составили $69(57,5 \%)$ человек, а без работы находились $51(42,5 \%)$ пациентов.

Менее половины исследуемых больных идиопатической эпилепсией имеют лишь средне-профессиональное образование и заняты на работе. 
При исследовании выявлено, что не зависимо от формы идиопатической эпилепсии, пола, возраста больных - 63 (52,5\%) человека проживают в сельской местности (районах, селах) области, а 57 (47,5\%) пациентов в городе. Но наличие высшего и средне-специального образования у больных идиопатической эпилепсией, проживавших в городе наблюдалось в большинстве случаев, чем среди пациентов, проживавших в сельской местности.

Средняя продолжительность заболевания

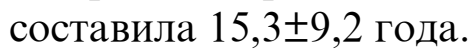

Возраст дебюта заболевания до 5 лет составил у $22(18,34 \%)$ больных, до 10 лет - у 36 $(30 \%)$ пациентов, до 15лет выявлено у 44 $(36,66 \%)$ больных, у 18 (15\%) человек - после 15 лет.

Пик дебюта заболевания эпилепсии проявился до 15 лет в большинстве случаев у $36,66 \%$ больных.

Исследование КЖ больных эпилепсией проводилось с использованием краткого опросника ВО3 для оценки качества жизни (WHOQOL-BREF). Краткий опросник WHOQOL-BREF состоит из 26 пунктов, которые оценивают следующие широкие области: физическое здоровье, психологическое здоровье, социальные отношения и окружающую среду. Хорошие оценки получены в сфере "Социальные отношения" $14,18 \pm 0,16$, где оцениваются близкие личные взаимоотношения индивида, возможность оказывать поддержку другим людям и получать поддержку от них. Значения остальных трех сфер можно рассматривать как относительно удовлетворительные. Показатели физической и психологической сфер находились на уровне средних значений (11 - 13 баллов по шкале ВОЗ КЖ 100).

Исследование позволило установить многочисленные различия в ряде демографических и клинических показателей, влияющих на КЖ больных эпилепсией. Результаты проведенных исследований показали, что женщины, в основном, хуже оценивали свое КЖ по сравнению с мужчинами.

В оценке КЖ были выявлены выраженные отличия и у разных возрастных групп.

Больные ИЭ старше 39 лет в отличие от молодых достоверно ниже $(\mathrm{p} \leq 0,05)$ оценивали свое функционирование в физической сфеpe и сфере социальных отношений. Общее КЖ также было достоверно $(\mathrm{p} \leq 0,05)$ ниже у больных старше 40 лет.

У больных ИЭ с дебютом эпилепсии в возрасте до 15 лет включительно и с более поздним началом заболевания обнаружены различия в оценках КЖ.

Отмечено, что больные с ранним дебютом заболевания достоверно выше $(\mathrm{p} \leq 0,05)$ оценили свое КЖ в физической и психологической сферах, сфере окружающей среды, и общее КЖ.

В возрасте начала заболевания у больных ИЭ существенно влияет на КЖ, поскольку в молодом возрасте больше возможности социальной и психической адаптации.

Достоверно хуже $(\mathrm{p} \leq 0,05)$ оценивали свое физическое и психологическое функционирование, социальные отношения больные с частыми и сложными припадками, что в очередной раз подтверждает тезис о припадках как об одном из главных дезадаптирующих факторов.

Для изучения роли социальных факторов и когнитивных дисфункций в оценке КЖ у больных ИЭ был проведен уровневый и структурный анализ влияния образования, трудовой занятости, семейного положения.

Это свидетельствует о низкой удовлетворенности своим КЖ и наличием социальной дезадаптации у инвалидизированной группы больных. А результаты исследований КЖ у больных ИЭ, имеющих высшее образование свидетельствовало об их лучшей психической и социальной адаптации. Анализ показателей КЖ больных ИЭ в зависимости от трудового статуса показал, что трудоустроенные пациенты несколько выше оценивали физическую сферу, социальные отношения, психологическое здоровье, чем неработающие, в том числе и инвалиды по заболеванию. В общей оценке КЖ инвалиды и неработающие, дали более низкие оценки КЖ во всех перечисленных сферах. Больные, состоящие в браке, отмечали достоверно большую удовлетворенность отношениями с родными и близкими, чем не- 
семейные пациенты. Это свидетельствует о том, что отсутствие семейной поддержки ухудшает психическую адаптацию больных. Больные ИЭ с легкими когнитивными расстройствами, оценивая КЖ по всем сферам опросника, были удовлетворены физическим, психологическим здоровьем, но снизили оценку социальным отношениям и окружающей среде. Пациенты с умеренными когнитивными нарушениями не очень высоко оценили КЖ по всем субсферам, снижая в основном по значениям психологического здоровья, социальным отношениям, окружающей среде - часто находясь в плохом настроении или состоянии тревоги или, депрессии.

\section{Выводы:}

Проведенный анализ результатов опрос- ника КЖ больных ИЭ показал зависимость КЖ от уровня образования, занятости на работе, учебной деятельности, инвалидизации, состояния когнитивных функций - уровня интеллекта, их положения в социуме.

Больные ИЭ оценили свое качество жизни, как плохое, что свидетельствовало об их не высоком реабилитационном потенциале, вероятно, связанным, с мало эффективной, неадекватной АЭ терапией или недоступностью дорогостоящих лекарственных средств.

Отмечено, что на КЖ больных ИЭ влияли демографические и клинические показатели (пол, возраст больных, формы эпилепсии, тип, частота припадков, место проживания, образование), а также степень когнитивных нарушений.

\title{
SUMMARY
}

\section{SOCIAL ADAPTATION AND QUALITY OF LIFE OF PATIENTS WITH EPILEPSY}

\author{
G.A. Duschanova, G.U. Tuksanbaeva \\ South Kazakhstan State Pharmaceutical Academy, Shymkent, Kazakhstan
}

The study aims to examine the quality of life and social adaptation of patients with idiopathic epilepsy was performed on 120 patients with idiopathic epilepsy among patients Neurology clinic and regional hospital in Shymkent. In the study revealed that regardless of the form of idiopathic epilepsy, gender, age of the patients - $63(52.5 \%)$ people live in rural areas (districts, villages) region, and $57(47.5 \%)$ patients in the city. But the presence of higher and specialized secondary education in patients with idiopathic epilepsy who were living in the city were observed in the majority of cases than among patients living in rural areas. The average duration of disease was 15.3 \pm 9.2 years. Age of onset of the disease up to 5 years was in $22(18.34 \%)$ patients, and 10 years - in $36(30 \%)$ patients, to 15 years was found in $44(36.66 \%)$ patients, $18(15 \%)$ patients - after 15 years. The peak onset of the disease epilepsy manifested to 15 years in most cases, $36.66 \%$ of patients. Analysis of the questionnaire QOL of patients with IE showed the dependence of the QOL level of education, employment, at work, learning activities, disability, cognitive function - the level of intelligence of their position in society. IE patients rated their quality of life as poor, who indicated that they were not high rehabilitation potential, probably associated with little effective therapy AE inadequate or prohibitively expensive medicines. It is noted that the QOL of patients with IE influenced by demographic and clinical variables (gender, age of patients, forms of epilepsy, type, frequency of seizures, place of residence, education), and the degree of cognitive impairment. 


\title{
XÜLAS习
}

\section{EPILEPSIYYALI XəSTOLӘRIN SOSİAL ADAPTASIYYASI VӘ HӘYAT KEYFIYYӨTI}

\author{
Q.A.Duşanova, Q.U.Tuksanbayeva \\ Cənub-Kazaxıstan Dövlat Farmosevtik akademiyası, Şimkənt, Kazaxıstan
}

\begin{abstract}
Tədqiqat zamanı idiopatik epilepsiyalı xəstələrin həyat keyfiyyəti və sosial adaptasiyası öyrənilmişdir. Şimkent ş. Kliniki xəstəxanasının nevroloji şöbəsində və poliklinikasında pasiyentlər arasında idiopatik epilepsiyalı 120 xəstə tədqiqata cəlb edilmişdir. Tədqiqat zamanı aydın olmuşdur ki, idiopatik epilepsiyanın formasından, pasiyentin cinsindən və yaşından asılı olmayaraq 63 nəfər (52,5\%)-i kəndlərdə (rayon, kənd), 57 nəfər $(47,5 \%)$ isə şəhərdə yaşayır. Ali və orta-ixtisas təhsili şəhərdə yaşayan idiopatik epilepsiyalı xəstələrdə kəndlərdə yaşayanlarla müqayisədə çox olmuşdur. Xəstəliyin orta davametmə müddəti 15,3 99,2 il təşkil etmişdir. Xəstəliyin debyut yaşı 5 yaşa qədər 22 nəfər (18,34\%), 10 yaşa qədər 36 nəfər (30\%), 15 yaşa qədər 44 nəfər (36,66\%), 18 nəfərdə (15\%) 15 yaşından sonra olmuşdur. Xəstəliyin debyutunun pik yaş dövrü əksər hallarda 15 yaşa qədər aşkarlanırdı - xəstələrin 36,66\%-i. İdiopatik epilepsiyalı xəstələrin həyat keyfiyyətinin sorğu anketi ilə analizi həyat keyfiyyətinin təhsilin səviyyəsindən, işindən, təhsil fəaliyyətindən, əlilliyindən, koqnitiv funksiyaların vəziyyətindən - intellektin səviyyəsindən, sosiumda vəziyyətindən asılı olduğunu göstərdi. İdiopatik epilepsiyalı xəstələr öz həyat keyfiyyətlərini pis qiymətləndirmişdirlər, bu da onların reabilitasiya potensiallarının yüksək olmadığına dəlalət edir. Bu, ehtimal ki, antikonvulsantlarla qeyri-adekvat müalicə, bahalı dərman preparatlarının əlçatmaz olması ilə əlaqədardir. Qeyd edilmişdir ki, idiopatik epilepsiyalı xəstələrin həyat keyfiyyətinə demoqrafik və klinik göstəricilər (cins, xəstələrin yaşı, epilepsiyanın formaları, tipi, tutmaların tezliyi, yaşayış yeri, təhsili) və koqnitiv funksiyaların pozulma dərəcəsi də təsir etmişdir.
\end{abstract}

Redaksiyaya daxil olub: 01.03.2013

Çapa tövsiyə olunub: 28.03.2013

Rayçi: R.L.Həsənov, t.e.d. 